\title{
DEPÓSITOS FOSFÁTICOS MARINHOS NA COSTA SUDESTE E SUL DO BRASIL: POTENCIAIS ÁREAS DE OCORRÊNCIA IDENTIFICADAS COM DADOS DE RETROESPALHAMENTO ACÚSTICO DO FUNDO E SEDIMENTOLÓGICOS ANALISADOS SOBRE MAPA BATIMÉTRICO 3D
}

\author{
Marcelo Peres de Pinho ${ }^{1}$, Lauro Saint Pastous Madureira², Lauro Júlio Calliari³, \\ Gilberto Henrique Griep ${ }^{4}$ e Caroline Vieira Cooke ${ }^{5}$
}

Recebido em 2 outubro, 2009 / Aceito em 27 dezembro, 2010 Received on October 2, 2009 / Accepted on December 27, 2010

\begin{abstract}
Bathymetric, sedimentological and seabed acoustic backscatter data were integrated into a 3D GIS (Geographic Information System). $38 \mathrm{kHz}$ echo sounders were used to collect data over 14,596 nautical miles during six fish biomass assessment cruises over the continental shelf, slope and adjacent oceanic regions between Chuí-RS $\left(34^{\circ} \mathrm{S}\right)$ and Cape São Tomé-RJ $\left(22^{\circ} \mathrm{S}\right)$, Brazil. The bathymetric set of data were complemented with satellite altimetry and also with data from general bathymetric charts in order to build a bathymetric grid with 5,397,090 points. From this grid, a 3D virtual representation of the seabed was generated, using the language for description of three-dimensional interactive environments X3D. Bottom features such as Rio Grande Cone and Terrace, São Paulo Plateau and others, were identified in the bathymetric maps. 3D GIS implementation allowed to analyze backscatter and sedimentological information over the bathymetric grid, demonstrating to be a useful tool to highlight areas with characteristically phosphatic deposits. 3D GIS proved to be more valuable than two-dimensional representations because allowed observation of details and interpretation of information from different not static viewpoints.
\end{abstract}

Keywords: marine acoustics, phosphate deposits, bathymetry, 3D GIS.

RESUMO. Dados batimétricos, sedimentológicos e de retroespalhamento acústico do fundo foram integrados em um SIG (Sistema de Informação Geográfica) 3D. Ecossondas operando na frequência de $38 \mathrm{kHz}$ foram utilizadas para coletar dados da costa brasileira, ao longo de 14.596 milhas náuticas. As operações ocorreram sobre a plataforma continental, talude e região oceânica adjacente, entre Chuí-RS ( $\left.34^{\circ} \mathrm{S}\right)$ e 0 Cabo de São Tomé-RJ $\left(22^{\circ} \mathrm{S}\right)$, Brasil. Os dados batimétricos obtidos por estas ecossondas durante seis cruzeiros de prospecção pesqueira foram complementados com informações de altimetria por satélite e outros cruzeiros de oportunidade, permitindo a criação de uma malha batimétrica com 5.397 .090 pontos. A partir desta malha, foi gerada uma representação 3D do fundo marinho utilizando a linguagem para descrição de ambientes tridimensionais interativos X3D. Feições de fundo como o Cone e o Terraço do Rio Grande, o Platô de São Paulo, além de outras, puderam ser identificadas nestes mapas batimétricos. 0 SIG 3D permitiu realizar o cruzamento das informações de retroespalhamento acústico e sedimentológicos sobre os mapas batimétricos, auxiliando na identificação das regiões com características típicas de depósitos fosfáticos. 0 SIG 3D mostrou-se vantajoso em relação às representações bidimensionais, pois permitiu a observação de detalhes e a interpretação das informações a partir de diferentes pontos de visão não estáticos.

Palavras-chave: acústica marinha, fosforita, batimetria, SIG 3D.

Universidade Federal do Rio Grande, Instituto de Oceanografia, Av. Itália, km 8, Campus Carreiros, Cx. Postal 474, 96203-000 Rio Grande, RS, Brasil. Fax: (53) 3233-6601

${ }^{1}$ Laboratório de Tecnologia Pesqueira e Hidroacústica. Tel.: (53) 3233-6528 - E-mail: ec5mpp@furg.br

${ }^{2}$ Laboratório de Tecnologia Pesqueira e Hidroacústica. Tel.: (53) 3233-6555 - E-mail: doclsm@furg.br

3 Laboratório de Oceanografia Geológica. Tel.: (53) 3233-6518 - E-mail: Icalliari@log.furg.br

${ }^{4}$ Laboratório de Oceanografia Geológica. Tel.: (53) 3233-6586 - E-mail: ggriep@log.furg.br

5 Laboratório de Tecnologia Pesqueira e Hidroacústica. Tel.: (53) 3233-6743 - E-mail: ocecvc@furg.br 


\section{INTRODUÇÃo}

0 rápido avanço de ferramentas como 0 geoprocessamento e a realidade virtual proporcionaram um novo desafio, que é representar o mundo real tridimensional em um ambiente computacional, no qual não se está limitado a uma representação convencional estática, mas dinâmica, com possibilidade de interação direta do usuário. Neste contexto, o objetivo deste trabalho foi utilizar uma ferramenta computacional no formato de um SIG 3D interativo para identificar potenciais depósitos fosfáticos na margem continental brasileira. A análise dos dados foi realizada na região compreendida entre o Arroio Chuí, RS (3444'S) e o Cabo de São Tomé, RJ $\left(22^{\circ} 00^{\prime} S\right)$, tendo sido feita a integração do retroespalhamento acústico e sedimentologia do fundo sobre a malha batimétrica 3D.

Os resultados dos estudos demonstraram que esta ferramenta ajudou na identificação de áreas com potencial para a ocorrência de depósitos fosfáticos. Nesta introdução, também são apresentados os conceitos de "Fosforita" e "Retroespalhamento acústico" que servirão para entendimento do estudo.

\section{Fosforita}

Os depósitos de fosfato são a maior fonte de fósforo, sendo um elemento nutriente essencial para a agricultura. Sua principal aplicação se dá na forma de fertilizante, sendo assim, de fundamental importância para a produção de alimentos.

As fosforitas são minerais autigênicos relacionados a elevados níveis de matéria orgânica nos sedimentos de fundo. Os depósitos estão associados ao clima, às convergências de correntes oceânicas e às baixas taxas de sedimentação terrígena (Riggs \& Burnett, 1990). Estes minerais são um dos principais recursos não-metálicos encontrados no fundo submarino (Silva \& Mello, 2005).

A formação das partículas autigênicas ocorre através de lentos processos que envolvem reações químicas entre substâncias dissolvidas na água e outras depositadas no fundo oceânico (Dias et al., 2004). As fosforitas desenvolvem-se frequentemente sob forma de pelotas ou nódulos de diâmetros que variam entre 0,1 mm e alguns centímetros. Estes nódulos chegam a formar camadas de alguns centímetros até dezenas de metros, intercalados com quantidades variáveis de material sedimentar detrítico (Silva \& Mello, 2005).

Os depósitos de fosforita são mais comuns em regiões tropicais, ocorrendo até uma profundidade máxima de $1.000 \mathrm{~m}$, cobrindo a borda da plataforma e talude superior, platôs marginais e bancos submarinos (Mero, 1965). Aparecem na forma de cascalhos, nódulos ou crostas de espessura variada e parecem estar associadas a zonas de ressurgência (upwelling), divergência e alta produtividade biológica (Pinet, 1998). Áreas de ressurgência caracterizam-se pelo elevado aporte de nutrientes (nitrogênio e fósforo) que elevam os índices de produção primária e matéria orgânica e, consequentemente, a formação e crescimento de grãos fosfáticos (Riggs \& Sheldon, 1990).

A ocorrência de nódulos fosfáticos no Terraço do Rio Grande foi observada durante dragagens realizadas na plataforma continental externa e talude superior em profundidades de 100 a $500 \mathrm{~m}$ (Klein et al., 1992). Silva \& Mello (2005) destacam a existência de nódulos de fosforita com teores de 15 a $16 \%$ de $\mathrm{P}_{2} \mathrm{O}_{5}$ na mesma área, a uma profundidade de cerca de $500 \mathrm{~m}$.

As características descritas acima, que estão relacionadas às áreas de ocorrência de fosforita, foram buscadas nos mapas 3D, pois indicam a existência da mesma.

\section{Retroespalhamento acústico do fundo}

0 retroespalhamento acústico (backscatter - BS) do fundo é medido por ecossondas. A proporção de energia retroespalhada é determinada pelo coeficiente de reflexão, que por sua vez é função da impedância acústica do meio (água) e do refletor, nesse caso o fundo (MacLennan \& Simmonds, 1992). A parte da onda acústica que atinge 0 fundo e retorna ao transdutor representa a energia retroespalhada (backscatter). Fundos planos e irregulares apresentam diferentes graus de espalhamento de energia assim como as propriedades físicas do sedimento e as propriedades volumétricas do subfundo também influenciam significativamente na resposta. Formas sedimentares como marcas de ondulação (ripple marks), a textura das rochas, a composição litológica ou mineralógica e os organismos que vivem no fundo também influenciam no sinal (Collins et al., 1996).

Neste estudo 0 sinal de retroespalhamento registrado por ecossondas operando a $38 \mathrm{kHz}$ foi usado na caracterização dos tipos de fundo relacionados à existência de fosforita.

\section{METODOLOGIA \\ Mapa batimétrico}

Foram utilizados dados batimétricos provenientes de seis cruzeiros de prospecção acústica pesqueira, realizados ao longo de 14.596 milhas náuticas (Fig. 1) da costa brasileira entre os anos de 1995 e 2001. Estes cruzeiros foram limitados ao norte pelo Cabo de São Tomé, RJ e ao sul pelo Arroio Chuí, RS. As linhas de sondagem foram realizadas perpendicularmente à costa, com espaçamento máximo de 20 MN entre linhas. 


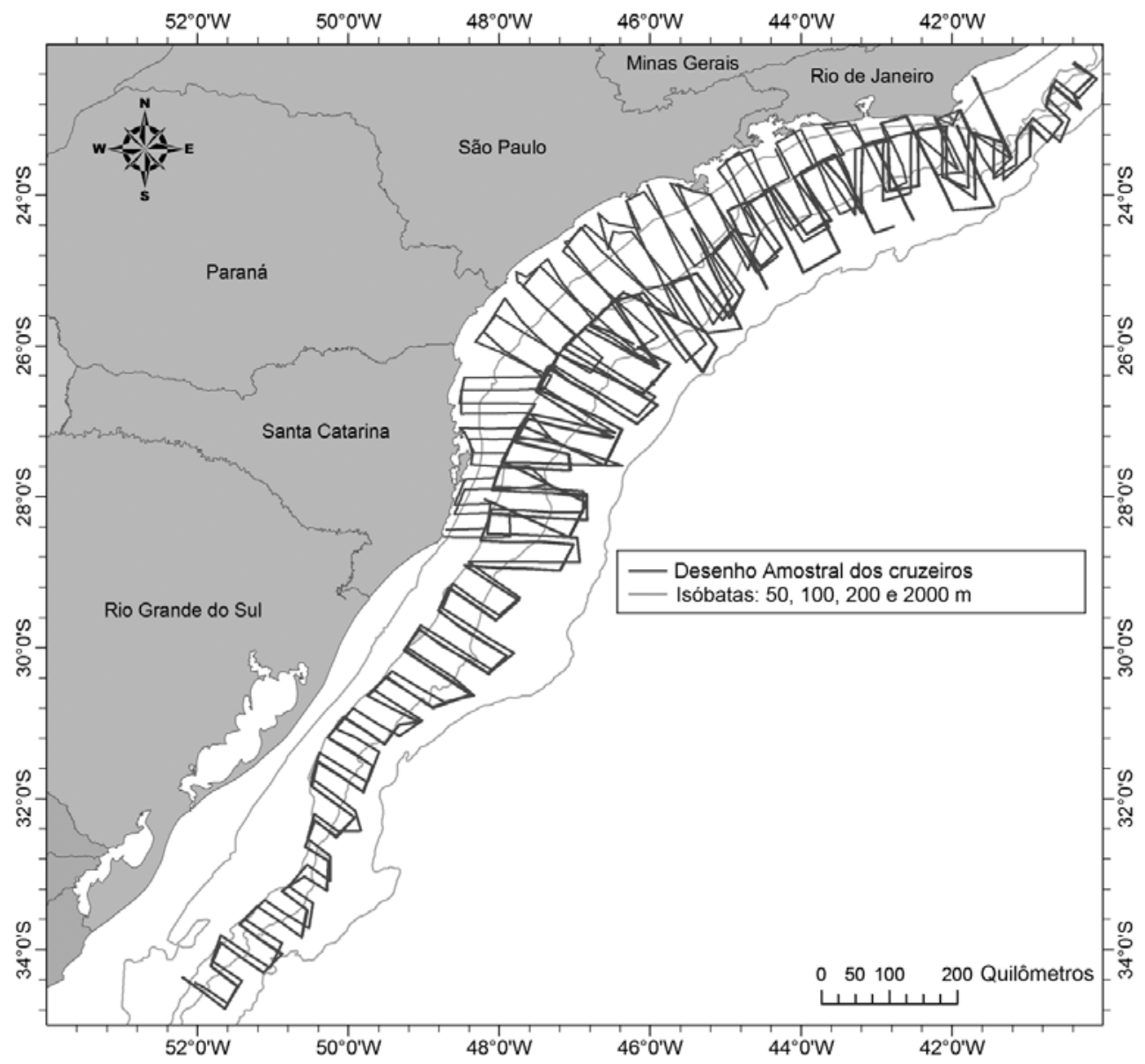

Figura 1 - Área de estudo com o desenho amostral dos seis cruzeiros de prospecção acústica pesqueira.

Para a coleta dos dados, foram utilizadas ecossondas científicas Simrad modelo EK500 (Simrad, 1996), calibradas utilizandose esfera de Carbeto de Tungstênio, conforme metodologia descrita por Foote (1982) e modificada por MacLennan \& Simmonds (1992). Os equipamentos operaram na frequência de $38 \mathrm{kHz}$ e os parâmetros configurados nas mesmas (Tab. 1) permaneceram constantes ao longo da realização do cruzeiro.

Tabela 1 - Parâmetros configurados para a ecossonda.

\begin{tabular}{|c|c|}
\hline Parâmetro & Configuração \\
\hline Limiar de Sv (aquisição) & $-80 \mathrm{~dB}$ \\
Taxa de emissão de pulso & Automático \\
Velocidade do som & $1534 \mathrm{~m} / \mathrm{s}$ \\
Duração do pulso & $1 \mathrm{~ms}$ \\
Resolução de aquisição & $10 \mathrm{~cm}$ \\
Largura de banda & Largo \\
Coeficiente de absorção & $10 \mathrm{~dB} / \mathrm{km}$ \\
Ângulo de sensitividade lon/tran & $21,9 / 21,9$ \\
Ângulo de feixe simétrico $(\Psi)$ & $-20,8 \mathrm{~dB}$ \\
TVG ( Time Varied Gain) & $20 \log \mathrm{R}+2 \alpha \mathrm{R}$ \\
\hline
\end{tabular}

Para adensar a malha batimétrica, foram acrescentados dados de altimetria obtidos por satélite. Os dados altimétricos utilizados são obtidos através de um sensor de micro-ondas instalado em uma plataforma orbital que realiza a varredura de aproximadamente $90 \%$ dos oceanos. A medição da profundidade é indireta e é função da variação de altura da superfície do oceano induzida pela influência do campo gravitacional do relevo submerso (geoide). Os dados utilizados foram publicados por Smith \& Sandwell (1997) e estão disponíveis em http://topex.ucsd.edu/.

As medições realizadas com o método gravimétrico sobre a plataforma e talude apresentam grande incerteza vertical. Os valores de gravimetria sofrem grande influência da proximidade dos sedimentos da costa. Esta incerteza vertical ainda não foi quantificada com precisão (Sandwell et al., 2001). Por este motivo, os autores decidiram incorporar aos dados altimétricos satelitais, dados batimétricos obtidos por navios de ocasião. Deste modo, pôde-se gerar uma malha batimétrica sobre a plataforma e talude da área de estudo com boa consistência de informações. 
0 banco de dados final reuniu os dados batimétricos e altimétricos satelitais e foi usado como entrada para a rotina de processamento de dados desenvolvida. Esta rotina usou as facilidades dos programas do pacote GMT - Generic Mapping Too/s (Wessel \& Smith, 1998). Os dados foram filtrados em blocos de $30 \times 30$ segundos de grau, sendo obtida a mediana dos valores de profundidade e de localização. Após a filtragem os dados foram interpolados para uma malha amostral com resolução de 30 segundos de grau (aproximadamente $926 \mathrm{~m}$ ) por uma rotina de curvatura continua "spline" com tensão, conforme metodologia descrita em Smith \& Wessel (1990) e utilizada por Ferreira et al. (2005).

A malha batimétrica gerada foi utilizada como base para a construção da representação 3D da área de estudo, sobre a qual foram incluídos os dados sedimentológicos e de retroespalhamento acústico do fundo.

\section{Modelagem 3D}

Para a construção do ambiente interativo 3D optou-se por utilizar a linguagem X3D, sobre o qual os diferentes dados foram incluídos. Um script X3D é um arquivo ASCII com uma eXtensão ".x3d", que pode ser editado em qualquer editor de texto. 0 padrão X3D facilita a separação de conteúdo por formatação, proporcionando uma maior simplicidade, legibilidade e 0 compartilhamento de conteúdo pela internet, podendo ser visualizado através de um browser, ou em um visualizador, como neste trabalho.

A representação 3D do mapa batimétrico base, sobre 0 qual as diversas informações foram integradas, foi gerada com um exagero vertical de 40 vezes, a fim de destacar as principais feições de fundo, tornando-as mais visíveis para o observador. $\mathrm{Na}$ representação 3D com sobreposição de dados de BS, foi utilizado um exagero vertical de 20 vezes para o mapa batimétrico base, a fim de facilitar a observação da variação deste parâmetro.

A representação 3D se mostrou vantajosa se comparada às representações bidimensionais tradicionais, como ilustra as Figuras $2 A$ e $B$.

Na representação 3D percebe-se que há maior facilidade de interpretação dos dados, com melhor visualização das feições geológicas do fundo. Além disso, a representação se mostra mais informativa e visualmente mais atrativa.

\section{Faciologia}

Neste trabalho foram utilizadas as Cartas de Sedimentos de Fundo geradas por Dias et al. (2004) no âmbito do Programa
REVIZEE (Recursos Vivos na Zona Econômica Exclusiva). Estas cartas de sedimento contêm aproximadamente 28.000 informações de amostras obtidas junto ao Banco Nacional de Dados Oceanográficos (BNDO/DHN) e aproximadamente 500 amostras oriundas de expedições do REVIZEE.

A amostragem de sedimentos superficiais foi realizada com busca fundos diversos e dragas, lançadas a partir de navios da Marinha do Brasil e de embarcações de instituições de pesquisa. As amostras das expedições do Programa REVIZEE foram analisadas em laboratórios para caracterização sedimentar, incluindo análise granulométrica e avaliação de teores de matéria orgânica e carbonato de cálcio (Dias et al., 2004). As diversas cartas geradas a partir destes dados foram integradas em um único mapa cobrindo toda a área de estudo. Este mapa foi sobreposto à superfície batimétrica 3D, possibilitando a análise e identificação das características típicas das regiões de fosforita. Para melhorar ainda mais a identificação foram integrados também as informações de retrosespalhamento acústico, conforme descrito a seguir.

\section{Retroespalhamento acústico do fundo}

Os dados de retroespalhamento acústico foram adquiridos durante 0 cruzeiro da série REVIZEE realizado no verão de 1997. É importante ressaltar que a configuração da ecossonda foi mantida constante durante a coleta dos dados, sendo somente modificado 0 alcance, em função da alteração das profundidades. Os efeitos do espalhamento esférico $(20 \log \mathrm{R})$ e absorção $(2 \alpha \mathrm{R})$, que atenuam o sinal acústico durante sua propagação na coluna d'água, foram compensados pelo sistema de ganho crono-variado (Função TVG - Time Varied Gain), conforme a distância do transdutor ao fundo (R).

Os dados de BS, em decibéis (dB), foram utilizados em sua totalidade, com exceção dos valores maiores do que $-5 \mathrm{~dB}$ e menores do que $-20 \mathrm{~dB}$. Os dados foram agrupados em quatro classes, de acordo com a classificação feita por Figueiredo Jr. \& Madureira (2004) e adotada por Cooke et al. (2007).

- -5 até $-10 \mathrm{~dB}$ : Representada nos mapas pela cor vermeIha (máxima refletividade acústica);

- -10 até -15 dB: Representada nos mapas pela cor amarela;

- -15 até -20 dB: Representada nos mapas pela cor verde;

- $<-20 \mathrm{~dB}$ : Representada nos mapas pela cor azul (mínima refletividade acústica). 

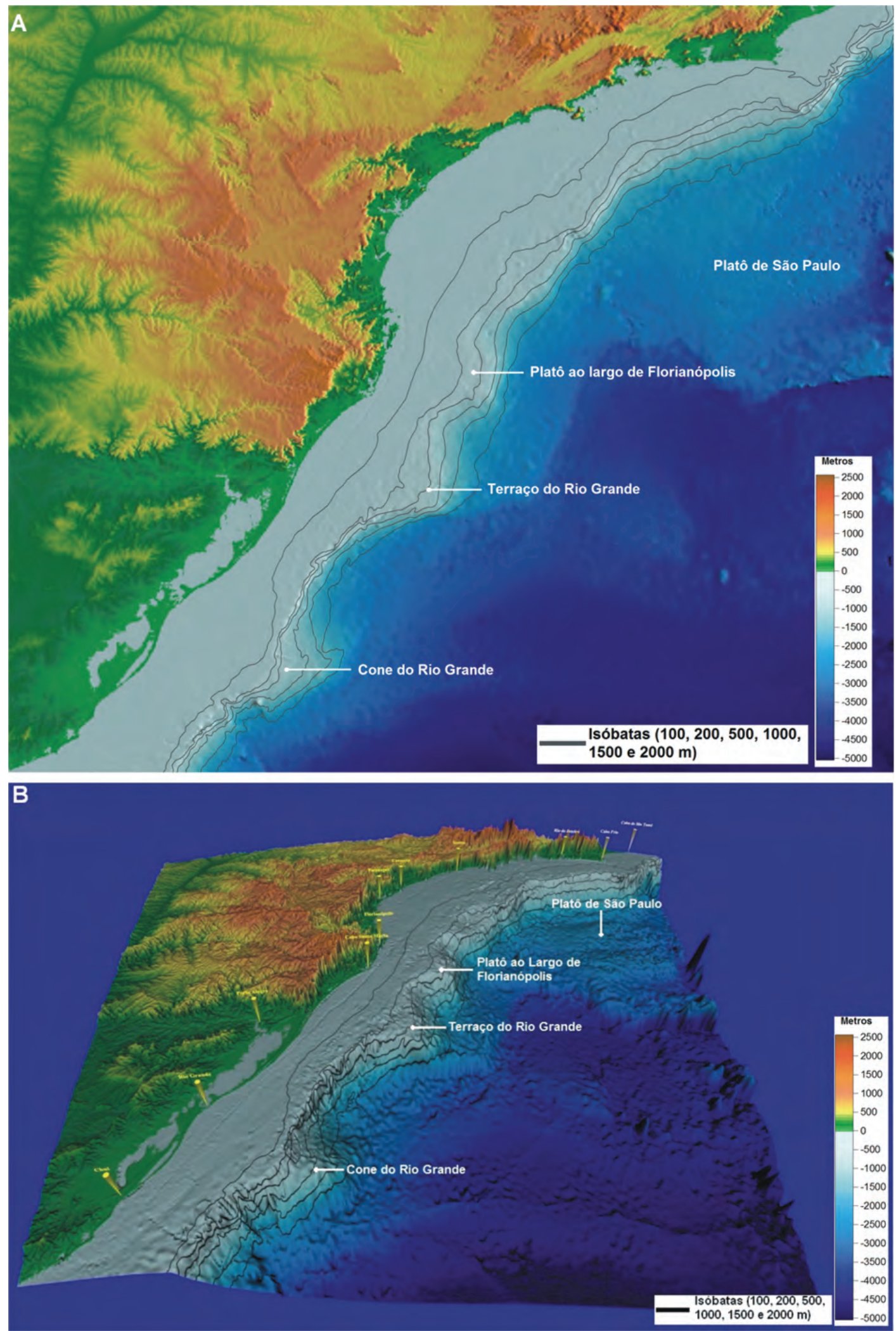

Figura 2 - A mesma região geográfica mostrada em 2D (A) e 3D (B). 
Os dados classificados foram utilizados na confecção de um mapa contendo também os dados sedimentológicos. Este mapa foi sobreposto sobre a superfície batimétrica 3D.

\section{DISCUSSÃO}

Os dados acústicos utilizados neste trabalho foram adquiridos em seis cruzeiros de prospecção pesqueira realizados entre o ChuíRS e o Cabo de São Tomé-RJ, totalizando 4.374.149 leituras batimétricas cobrindo a faixa de profundidade de 10 a $2.000 \mathrm{~m}$. A maior concentração de dados ocorreu na faixa dos 100 aos 200 m, 0 que corresponde à região da plataforma externa e talude superior da Margem Continental Sul Brasileira (Tab. 2).

Tabela 2 - Número de leituras acústicas por faixa batimétrica.

\begin{tabular}{|c|c|}
\hline Faixa batimétrica $(\mathrm{m})$ & $\mathrm{N}^{\circ}$ de amostras \\
\hline $10-100,9$ & 644.283 \\
$101-200,9$ & 2.113 .234 \\
$201-500,9$ & 759.560 \\
$501-1.000,9$ & 587.875 \\
$1.001-1.500,9$ & 226.933 \\
$1.501-2.191,7$ & 42.264 \\
\hline Total de amostras & 4.374 .149 \\
\hline
\end{tabular}

Cruzeiros de prospecção acústica pesqueira não objetivam, em primeiro plano, a aquisição de dados batimétricos, mas sim 0 mapeamento da distribuição e abundância de espécies de interesse comercial e ecológico. Embora sejam de excelente qualidade, os dados batimétricos de cruzeiros de prospecção acústica pesqueira geralmente são adquiridos sob uma malha com grande espaçamento (da ordem de 10 a 20 milhas náuticas) entre perfis, o que impede a elaboração de mapas batimétricos com boa resolução, baseados exclusivamente nestes dados. Por esta razão, torna-se necessário a utilização de dados de outras fontes a fim de preencher a malha batimétrica, o que foi realizado com a altimetria por satélite.

A utilização de satélites representa uma forma mais barata, rápida e eficiente de mapear remotamente o fundo oceânico (Sandwell et al., 2002). A resolução deste método é função tanto dos erros de medida do instrumento quanto do tamanho da feição de fundo, assim, uma feição é identificável desde que a mesma destaque-se frente ao ruído de fundo, causado pelos erros de medição (Sandwell et al., 2002). Ainda, segundo os autores, dependendo do ruído gerado pelas ondulações na superfície do mar, é possível identificar feições não menores do que duas vezes a profundidade local.

Aos dados de altimetria por satélite, nos setores em que possuem pouca precisão, foram integradas informações batimétricas provenientes de navios de ocasião, somand0 1.022.941 entradas. Assim, o banco de dados batimétricos final totalizou 5.397 .090 leituras batimétricas dispostas entre os 2 e os $5.000 \mathrm{~m}$ e que incluem dados de prospecção pesqueira, altimetria por satélite e navios de ocasião. Técnicas de filtragem e interpolação foram aplicadas sobre este banco, a fim de gerar uma malha batimétrica com resolução de 30 segundos de grau ou, aproximadamente, $926 \mathrm{~m}$ entre pontos. A malha batimétrica final gerada inclui as regiões da plataforma continental, o talude e a região oceânica das Bacias de Pelotas e Santos, tendo sido utilizada como base para a criação da representação 3D.

A Figura 2B, mostrada anteriormente, ilustra o mapa batimétrico 3D base, com destaque para as principais feições de fundo identificadas. 0 mapa batimétrico está representado com um exagero vertical de 40 vezes a fim de destacar as principais feições de fundo.

A fim de facilitar a localização geográfica das feições oceânicas a partir de referências em terra, foram incorporados ao mapa dados de elevação do continente. Os dados possuem resolução de 30 segundos de grau e estão disponíveis em http://edcdaac.usgs.gov/gtop030/gtopo30.asp.

\section{A sedimentologia, o BS e a presença de fosforita}

Os dados batimétricos, sedimentológicos e de retroespalhamento acústico do fundo foram utilizados para identificar locais com a possível presença de depósitos fosfáticos. Segundo Figueiredo Jr. \& Madureira (2004) as 4 classes de BS estabelecidas, podem ser correlacionadas a 10 classes sedimentares definidas a partir do diagrama triangular tipo Shepard. Os fundos mais duros e compactados apresentam maior reflexão, sendo representados nos mapas e nos ecoperfis de dureza de fundo pela cor vermelha. Os fundos menos reflexivos, ou de característica lamosa, foram representados na cor azul.

Os dados classificados foram utilizados na confecção de um mapa sobrepondo os dados sedimentológicos e de retroespaIhamento acústico de fundo. Posteriormente este mapa foi modificado e utilizado como textura sobre a superfície 3D gerada, conforme pode ser observado na Figura 3. Isto possibilitou a interpretação dos dados de forma integrada.

A partir da representação 3D foi possível identificar áreas com considerável correspondência entre os dados de BS e sedimentológicos. As Figuras 4 e 5 ilustram áreas ao largo de Cabo Frio-RJ e ao largo da Ilha de São Sebastião-SP, respectivamente, nas quais os dados de BS indicam alta refletividade acústica, característica de fundos duros, justamente sobre áreas 


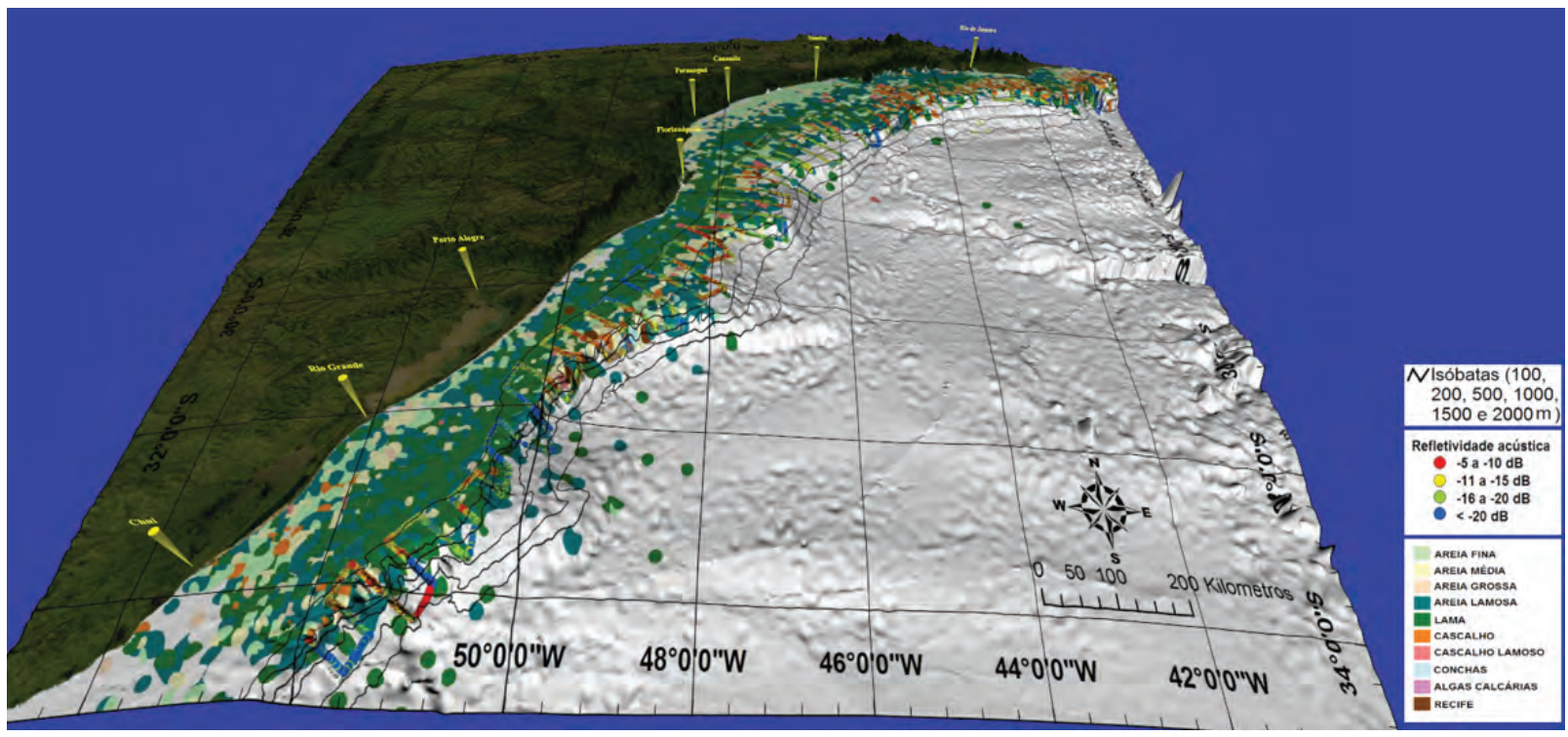

Figura 3 - Visão geral do mapa batimétrico 3D com sobreposição de dados sedimentológicos e de retroespalhamento acústico do fundo.

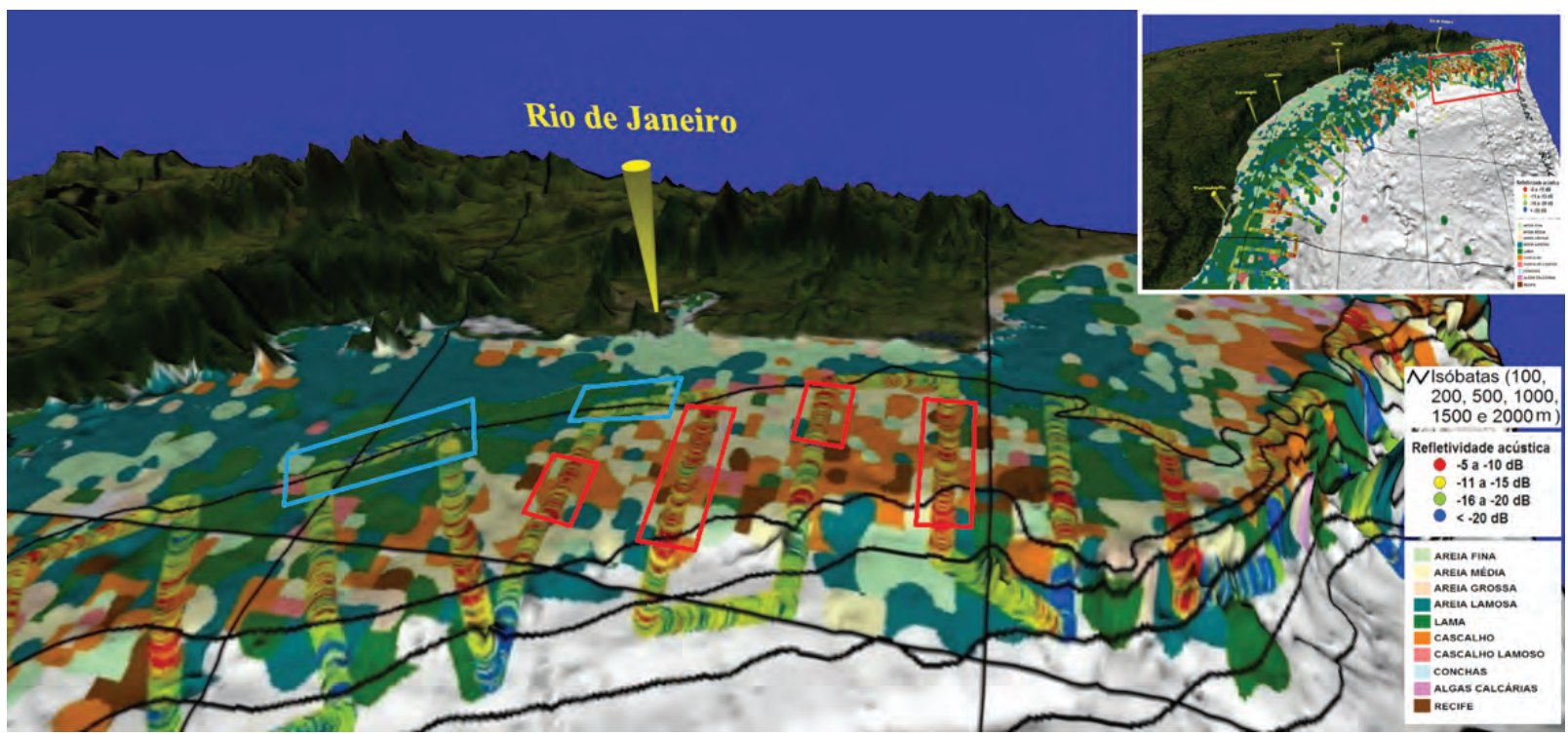

Figura 4 - Área ao largo de Cabo Frio com considerável correspondência entre os dados de BS e sedimentológicos. As áreas com fundos duros com altos valores de BS estão indicados em vermelho, enquanto os fundos lamosos com baixos valores de BS estão indicados em azul.

com fundos arenosos, de cascalho e biodetríticos (conchas e algas calcárias). Estas áreas estão indicadas em vermelho no mapa. Também é possível observar nestas figuras áreas com considerável correspondência entre baixos valores de BS sobre sedimentos lamosos. Estas áreas estão indicadas em azul.

A correspondência entre os dados de retroespalhamento acústico de fundo e sedimentológicos pôde ser identificada em outras regiões dentro da área de estudo. Um exemplo é mostrado na Figura 6 que ilustra área ao sul do Cabo de Santa
Marta Grande-SC, onde é possível observar baixos valores de BS (fundos menos duros), sobre área com fundo de lama e areia lamosa, bem como áreas com altos valores de BS sobre fundos considerados duros como cascalho lamoso e conchas, conforme mostra a carta sedimentológica. As áreas de fundos duros e menos duros estão indicadas na figura pelas cores vermelha e azul respectivamente.

Cabe ressaltar que os dados sedimentológicos e de BS não são totalmente coincidentes em função do número de amos- 


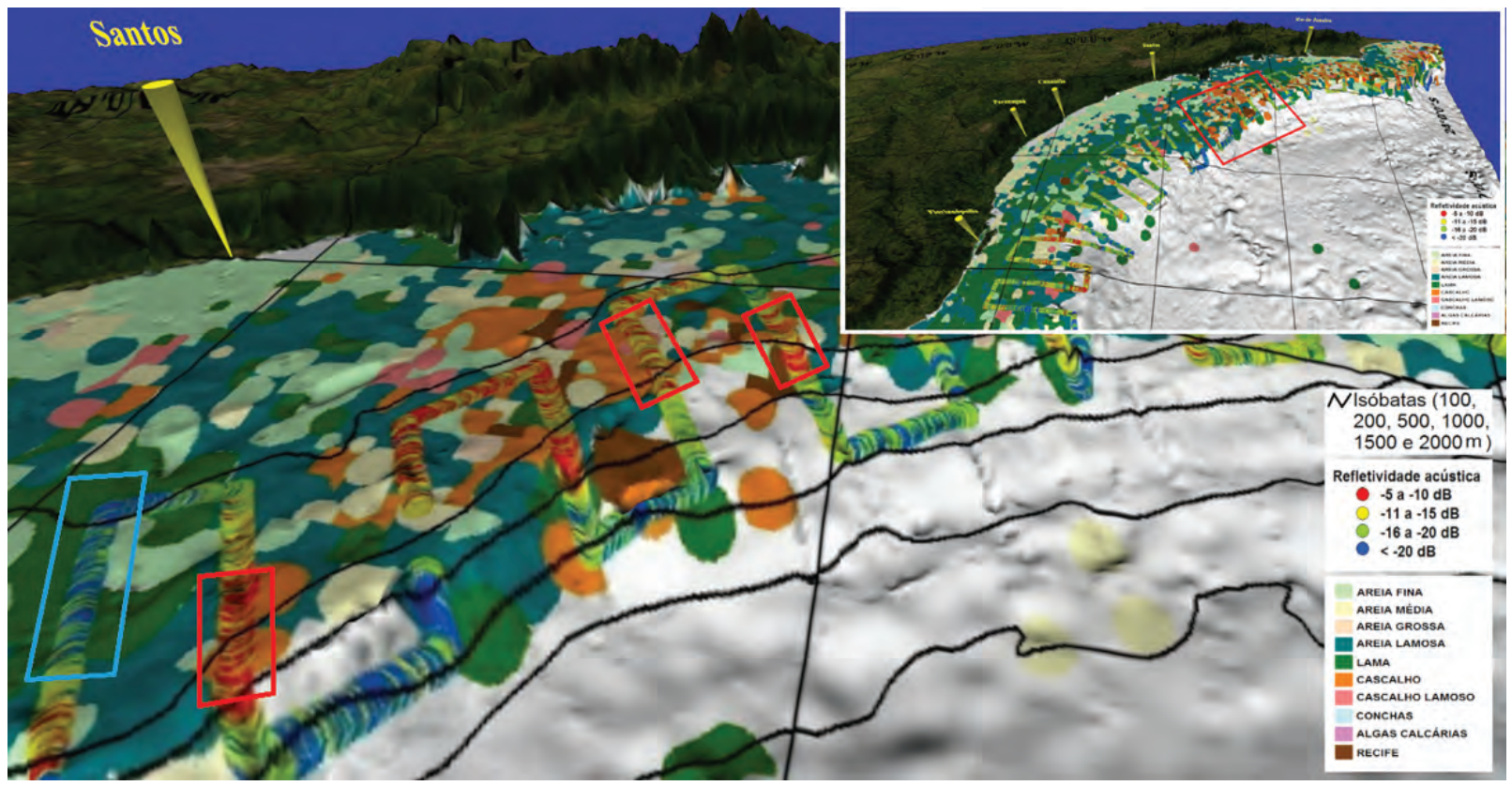

Figura 5 - Área ao largo da llha de São Sebastião com considerável correspondência entre os dados de BS e sedimentológicos. As áreas com fundos duros com altos valores de BS estão indicados em vermelho, enquanto os fundos lamosos com baixos valores de BS estão indicados em azul.

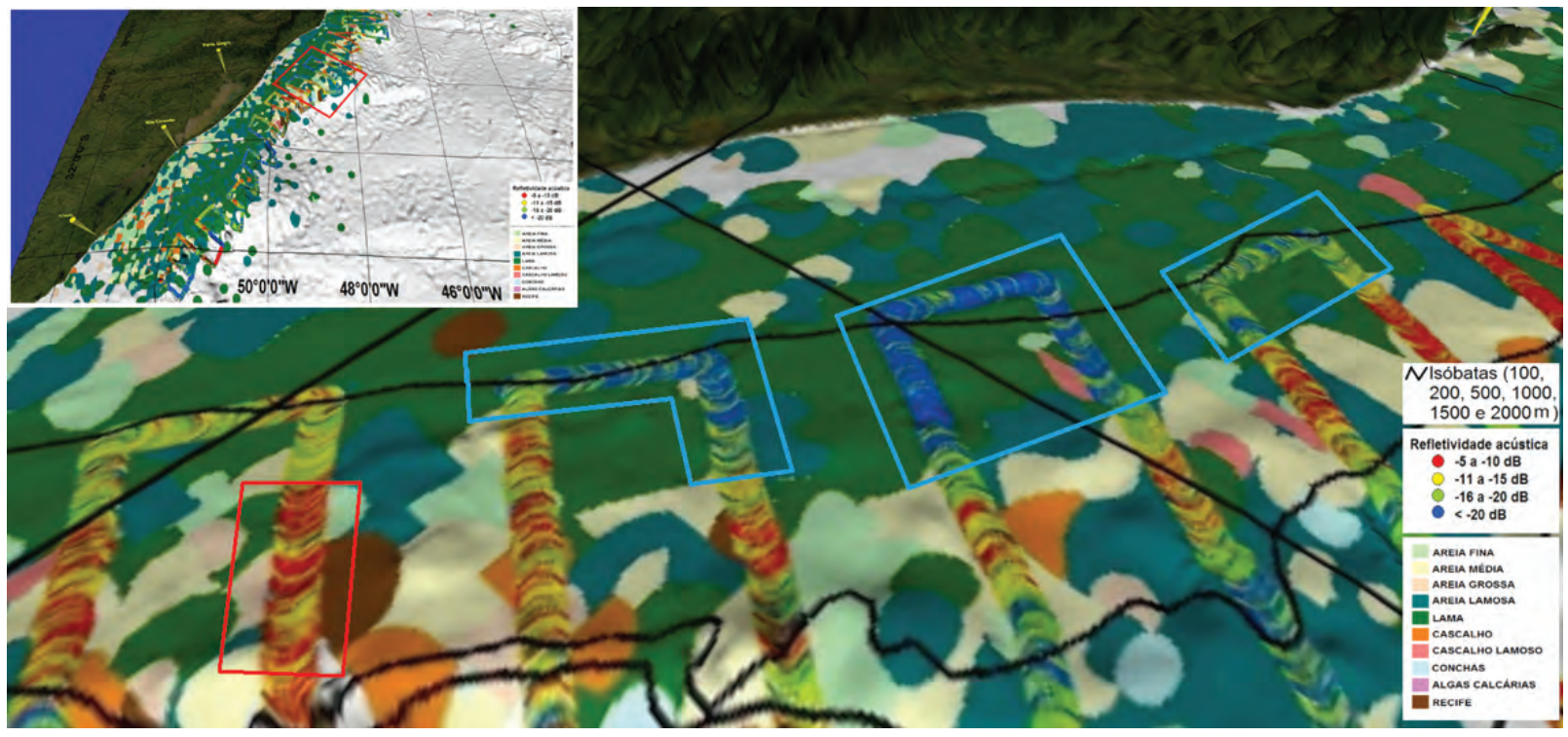

Figura 6 - Área ao sul do Cabo de Santa Marta Grande com considerável correspondência entre os dados de BS e sedimentológicos. As áreas com fundos duros com altos valores de BS estão indicados em vermelho, enquanto os fundos lamosos com baixos valores de BS estão indicados em azul.

tras de cada método. Os dados sedimentológicos provém da interpolação das amostras geológicas de fundo (dragas), que possuem baixa densidade espacial. Já os registros de BS são gravados com maior densidade amostral, sendo registrados a cada pulso da ecossonda. Consequentemente, a resolução dos dados sedimentológicos é consideravelmente baixa (baixo número de amostras) em algumas áreas, enquanto os dados de BS possuem um número elevado de registros ao longo dos perfis. Por outro lado, os dados de BS têm o problema intrínseco dos movimentos de balanço (rol/) e caturro (pitch) que podem afetar 0 BS medido. Estes movimentos fazem com que 0 ângulo de incidência dos feixes sofra variação, gerando diferentes valores de 
BS para um mesmo fundo. Este problema é compensado pelo elevado número de leituras realizadas por minuto, que permitem 0 cálculo de valores médios de BS.

A análise de BS/sedimentos citada anteriormente foi usada para mapear áreas com possível presença de depósitos fostáticos. Fundos duros e irregulares, identificados por altos valores de BS e pelos ecoperfis batimétricos gerados por Cooke et al. (2007) foram selecionados conjuntamente com os mapas de fundo gerados por Dias et al. (2004). Como prováveis candidatos à presença de depósitos fosfáticos foram considerados trechos dos perfis duros e irregulares, em profundidades inferiores a $1.000 \mathrm{~m}$, conforme as características descritas na Introdução no item Fosforita, e que estão relacionadas às áreas de ocorrência de depósitos fosfáticos.

Os perfis foram numerados sequencialmente, de forma crescente de norte a sul, com o objetivo de facilitar a localização nos mapas e o seu referenciamento no texto.

No extremo norte da área de estudo os perfis 02, 06 e 08, apresentaram as características consideradas indicativas da presença de fosforita. A Figura 7A ilustra a localização dos perfis e o contexto dos mesmos em relação ao BS e a sedimentologia da área. Todos os perfis apresentaram trechos com alta refletividade acústica em setores dentro da profundidade considerada de ocorrência da fosforita. Além disso, a informação sedimentológica apresenta boa correlação entre a dureza do fundo e a ocorrência de substratos duros na área de realização dos perfis.

A Figura 7B ilustra 0 ecoperfil de BS do Perfil 02. As diferentes classes de BS são representadas por diferentes cores, conforme detalhado no item Metodologia. 0 tamanho do traço do fundo adotado, também manteve proporcionalidade com os valores de reflexão do fundo, sendo menores nos registros de maior valor de BS (fundo duro; menor penetração de energia acústica no sedimento), e maiores nos de menor valor de BS (fundo mole; maior penetração de energia acústica no sedimento). Os trechos 1 e 2 do Perfil 02, indicados na figura, representam as principais áreas de fundo duro (alto BS) sobre fundo de cascalho, conforme mostrado no mapa sedimentológico.

Os perfis 02,06 e 08 estão localizados ao largo de Cabo Frio-RJ que é uma região de grande produtividade biológica, onde a ocorrência de ressurgências é frequente, conforme afirmam Castro et al. (2006), Gandini \& Madureira (2007), Möller Jr. et al. (2008) e Piola et al. (2008). Esta característica é um indicativo que esta área pode apresentar a ocorrência de fosforita, conforme discutido na Introdução no item fosforita.

Os perfis 28 a 30 e 32 a 36, realizados ao largo do Cabo de Santa Marta Grande-SC, também apresentaram características in- dicativas da presença deste mineral. A Figura 8 ilustra a localização geográfica dos perfis e 0 cruzamento com as informações de BS e de sedimentologia. Os perfis apresentaram trechos com alto retroespalhamento acústico em setores dentro da profundidade considerada de ocorrência da fosforita. Este alto retroespaIhamento acústico, indicativo de fundos duros, pode ser confirmado em alguns dos perfis a partir do cruzamento com os dados sedimentológicos, que indicam a ocorrência de substratos duros na área de realização dos perfis. Cabe salientar que os dados não são totalmente coincidentes devido a fatores já mencionados no texto.

Para fins de exemplificação a Figura 9 ilustra o Perfil 33. Os trechos 1 e 2 representam as áreas com potencial ocorrência de fosforita. Estes trechos também estão destacados na Figura 8.

0 Cabo de Santa Marta Grande, assim como a região de Cabo Frio, apresenta alta produtividade biológica e, eventualmente, processos de ressurgência, conforme afirmam Möller Jr. et al. (2008) e Castro et al. (2006). Por fim, os perfis 35 e 36 foram realizados sobre 0 Terraço do Rio Grande, área na qual Klein et al. (1992) relataram a ocorrência de nódulos fosfáticos.

Klein et al. (1992) sugerem que os ecoregistros de fosforita sejam caracterizados por irregularidades no fundo, apresentando-se na forma de "pináculos" bem destacados. A fim de verificar esta observação, procedeu-se a uma busca nos ecoregistros impressos em papel em todos os perfis identificados com potencial ocorrência de fosforita, objetivando identificar a presença de irregularidades de fundo que pudessem caracterizar a ocorrência de depósitos fosfáticos. Infelizmente, a escala utilizada no cruzeiro de 1997, tanto na construção dos ecoperfis de BS quanto na impressão dos ecogramas, não foi ideal para esta análise.

A fim de exemplificar ecoregistros de fundo, assumidamente típicos de depósitos fosfáticos, realizou-se uma busca nos ecogramas impressos em outro cruzeiro da série REVIZEE. Este cruzeiro, de menor duração, foi realizado no verão de 1999 em área ao sul do Cabo de Santa Marta Grande, com objetivo de estudar em detalhe ocorrências de peixes próximos do fundo. A Figura 10 ilustra possiveis fundos fosfáticos encontrados próximos à área dos perfis 35 e 36 (Fig. 8).

0 cruzamento das diversas informações num ambiente SIG $3 \mathrm{D}$, que possui ferramentas para análise 3D de forma dinâmica e interativa, permitiu a seleção de áreas com potencial ocorrência de depósitos fosfáticos. A confirmação da existência de depósitos depende da realização de amostragens de fundo nas áreas identificadas. Portanto, este estudo possui importância, pois permite indicar as áreas prioritárias de buscas nas próximas expedições. 


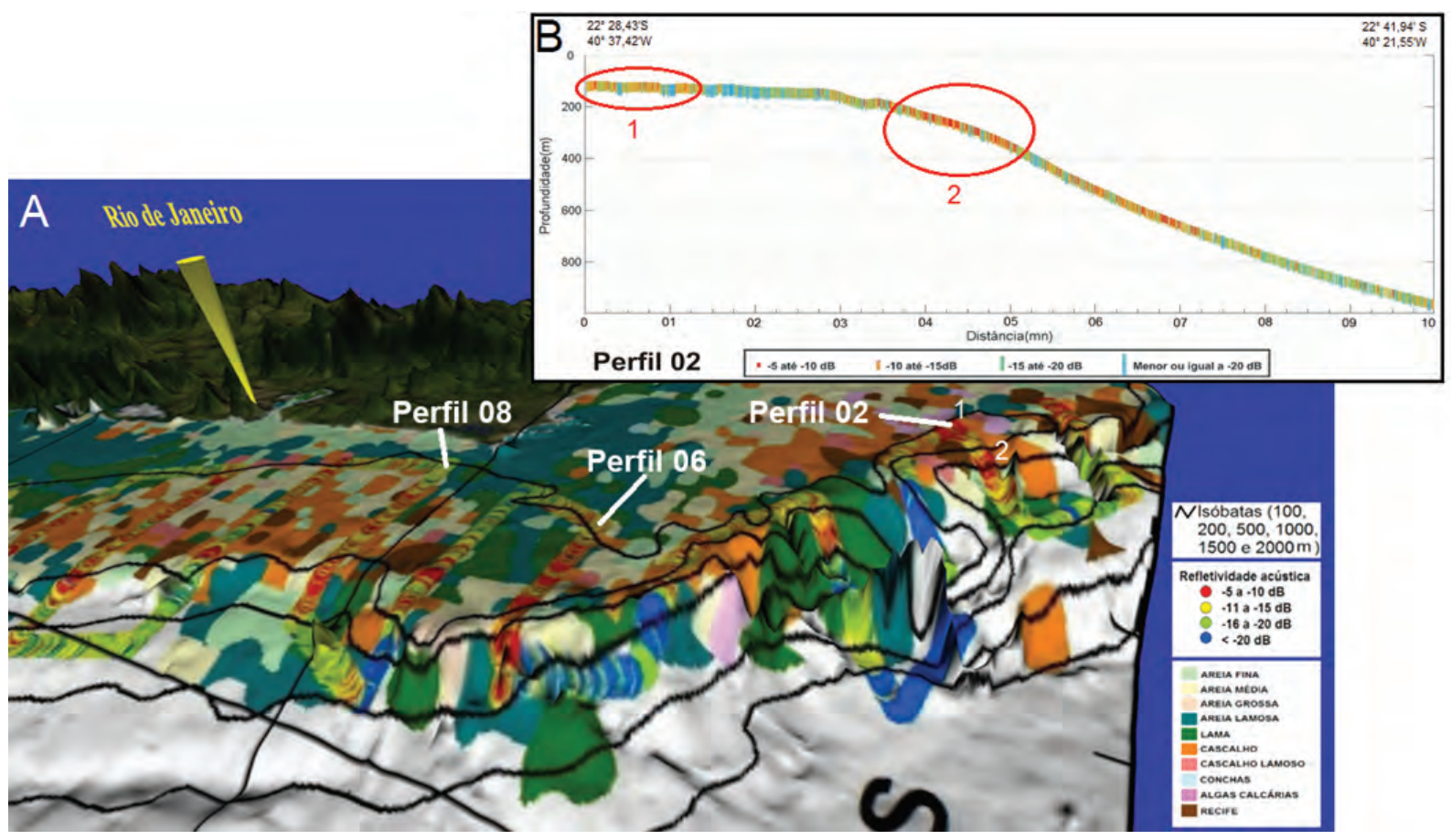

Figura 7 - Perfis 02, 06 e 08 com características compatíveis com a presença de fosforita, localizados próximo a Cabo Frio (A) e 0 ecoperfil de BS do Perfil 02 (B). Os trechos 1 e 2 indicam áreas com potencial presença de fosforita.

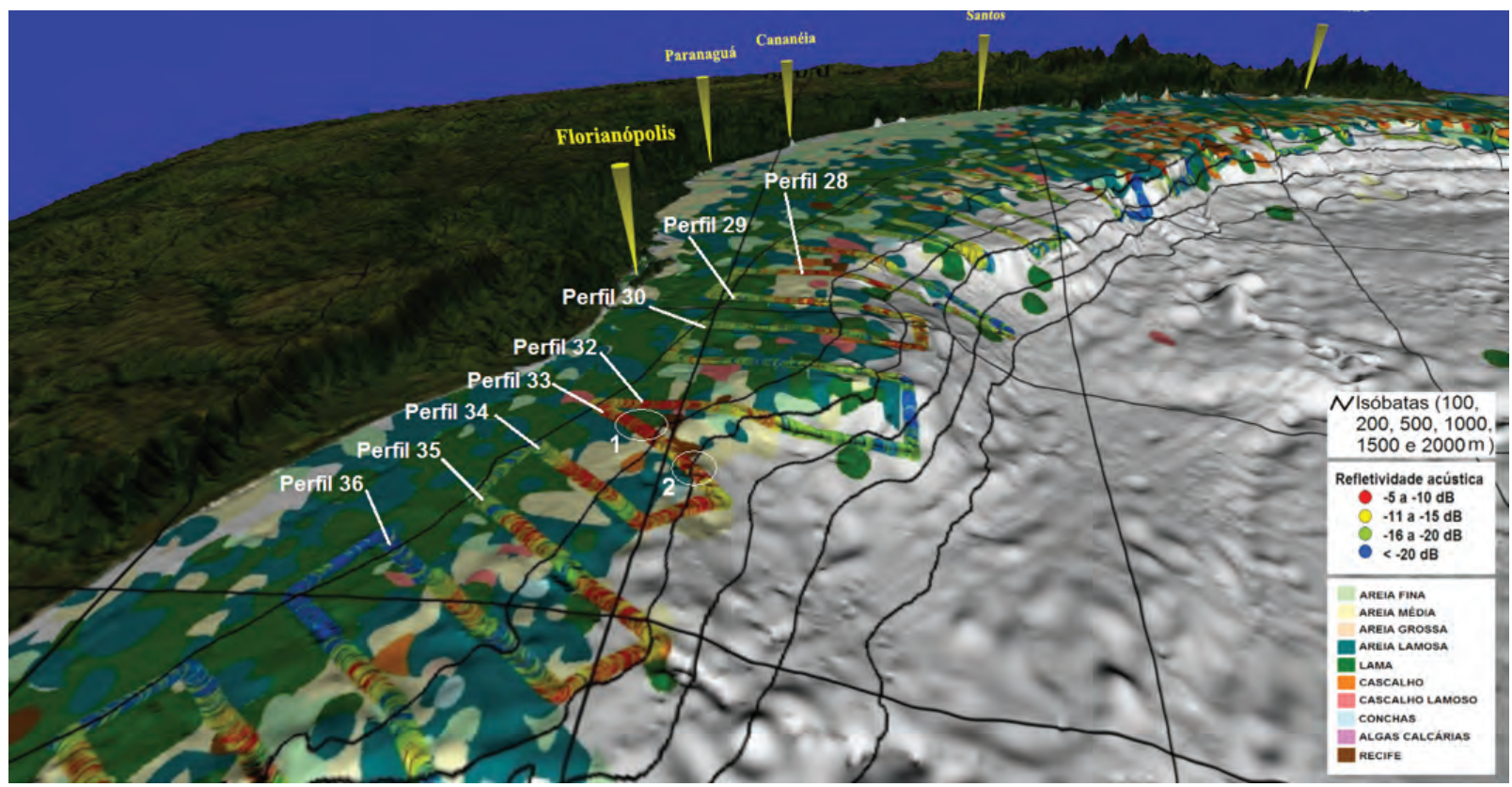

Figura 8 - Perfis 28 a 30 e 32 a 36, localizados ao largo do Cabo de Santa Marta Grande, e com características compatíveis com a presença de fosforita.

\section{CONCLUSÃO}

A representação virtual 3D do fundo oceânico desenvolvida neste trabalho mostrou-se vantajosa se comparada a mapas ou figuras 2D estáticas. Ao contrário destas representações, o SIG 3D permitiu ao observador analisar a informação disponível, a partir de diferentes pontos de visão, que favoreceram a observação de detalhes e a interpretação destas informações. Além disso, a capacidade de integrar dados de diferentes naturezas, também 

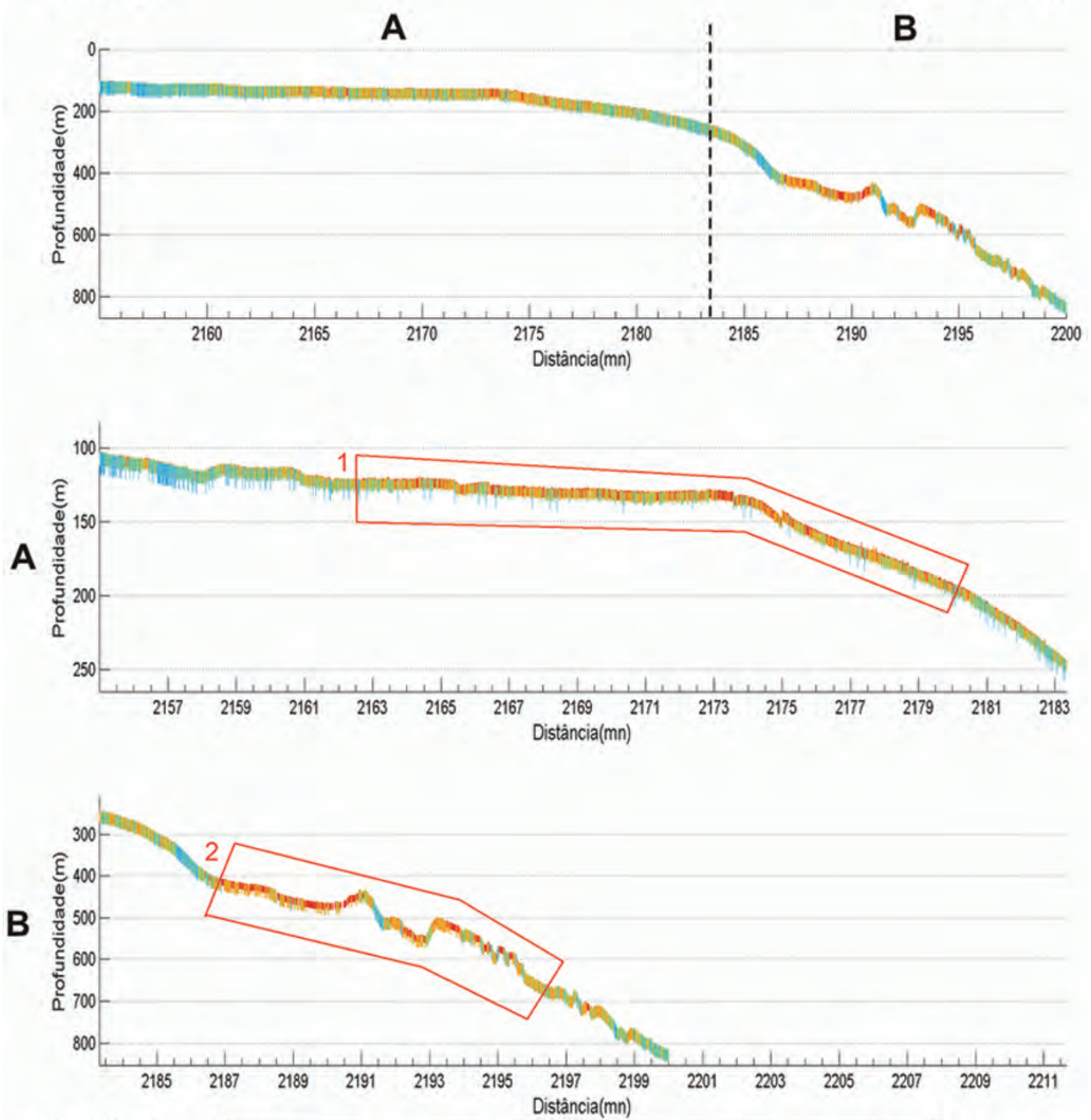

PERFIL 33

\begin{tabular}{|ll|l|l|}
\hline-5 até $-10 \mathrm{~dB}$ & $1-10$ até $-15 \mathrm{~dB}$ & -15 até $-20 \mathrm{~dB}$ & Menor ou igual a $-20 \mathrm{~dB}$ \\
\hline
\end{tabular}

Figura 9 - Ecoperfil de BS do Perfil 33. A e B são subdivisões do primeiro perfil visando maior detalhamento das feições e a observação das irregularidades a partir da diferenciação de escala. Os trechos 1 e 2 indicam áreas com potencial presença de fosforita.

mostrou-se eficiente, pois permitiu analisar os dados de forma conjunta em um ambiente computacional dinâmico e interativo que possibilitou avaliar as relações entre os diferentes tipos de dados.
0 mapa batimétrico gerado representa, por si só, uma meIhora significativa em relação às representações geradas anteriormente com os mesmos dados. A partir dele foi possível identificar de forma mais evidente algumas das principais feições de fundo 

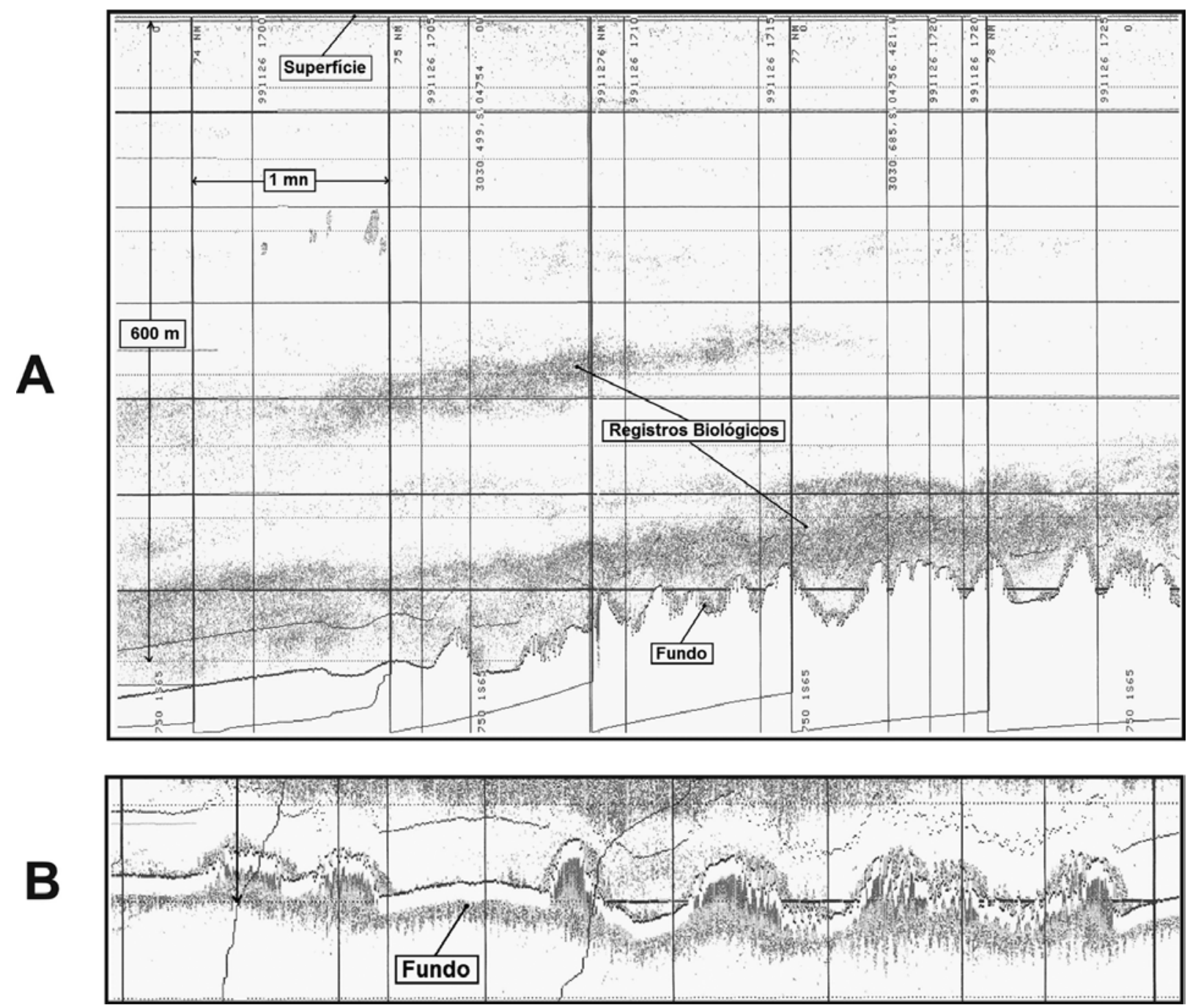

Figura 10 - (A) Ecograma ilustrando potencial fundo fostático registrado no cruzeiro REVIZEE, realizado no verão de 1999, próximo ao Cabo de Santa Marta Grande. (B) Detalhe de um registro de fundo ilustrando irregularidades na forma de pináculos, característicos da presença de fosforita.

presentes na área de estudo, tais como: 0 Cone do Rio Grande, 0 Terraço do Rio Grande e o Platô de São Paulo. 0 mesmo é válido para as diversas informações incluídas na representação virtual 3D, em especial a sedimentologia, que pôde ser analisada sobre a superfície batimétrica tridimensional.

Neste trabalho, buscou-se a identificação de áreas que, por suas características, pudessem indicar a presença de depósitos fosfáticos. Algumas áreas foram identificadas em regiões como 0 Cabo Frio e, principalmente, no Cabo de Santa Marta Grande, que são áreas conhecidas por eventos de ressurgência, que aportam grande quantidade de matéria orgânica. A identificação de áreas com ressurgência associadas a irregularidades no fundo pode indicar áreas atualmente propícias à formação desses depósitos, a exemplo de depósitos que ocorrem hoje na costa Sudoeste da África do Sul. Apesar dos indícios, a presença de depósitos fosfáticos nessas áreas só pode ser confirmada a partir de amostragens de fundo especificas, sendo que os pontos de amostragem e o tipo de amostradores necessários poderão ser determinados a partir das informações geradas neste trabalho.

\section{AGRADECIMENTOS}

À Agência Nacional do Petróleo, Gás Natural e Biocombustíveis/ Programa de Recursos Humanos PRH-27, a toda equipe do Laboratório de Tecnologia Pesqueira e Hidroacústica da FURG e ao Comandante do N.Oc. Atlântico Sul, Homero Pujeaux Alvariza e sua tripulação. 


\section{REFERÊNCIAS}

CASTRO BM, LORENZZETTI JA, SILVEIRA ICA \& MIRANDA LB. 2006. Estrutura Termohalina e Circulação na Região entre o Cabo de São Tomé (RJ) e o Chuí (RS). In: ROSSI-WONGTSCHOWSKI CLDB \& MADUREIRA LSP (Orgs.). 0 Ambiente Oceanográfico da Plataforma Continental e do Talude na Região Sudeste-Sul do Brasil. Editora da Univ. de São Paulo, p. 11-120.

COLLINS W, GREGORY R \& ANDERSON J. 1996. A Digital Approach to Seabed Classification. Sea Technology, 37(8): 83-87.

COOKE CV, MADUREIRA LSP, GRIEP GH \& PINHO MP. 2007. Análise de dados de ecossondagem de fundo oriundos de cruzeiros realizados entre Fortaleza (CE) e Chuí (RS) com enfoque na morfologia e tipos de fundo. Revista Brasileira de Geofísica, 25(4): 443-457.

DIAS GTM, EL ROBRINI M, FREIRE GSF \& FIGUEIREDO Jr AG. 2004. Cartas de Sedimento de Fundo. Áreas da Oceanografia Geológica (Sul, Central, Nordeste e Norte) - Programa de Avaliação do Potencial Sustentável dos recursos vivos na Zona Econômica Exclusiva. REVIZEE. CD-ROM de Cartas Sedimentológicas. Disponível em:

<http://www.mma.gov.br/ port/sqa/projeto/revizee> . Acesso em: 1 abr. 2007.

FERREIRA CS, MADUREIRA LSP, KLIPPEL S, WEIGERT SC, HABIAGA RGP \& DUVOISIN AC. 2005. Mapas do relevo marinho das regiões sudeste, sul e central do Brasil: acústica e altimetria por satélite. Série Documentos Técnicos do Programa REVIZEE - Score-Sul. São Paulo, Instituto Oceanográfico - USP. 40 pp.

FIGUEIREDO Jr AG \& MADUREIRA LSP. 2004. Topografia, composição, refletividade do substrato marinho e identificação de províncias sedimentares na Região Sudeste-Sul do Brasil. Série Documentos Técnicos do Programa REVIZEE - Score-Sul. São Paulo, Instituto Oceanográfico - USP. 64 pp.

F00TE KG. 1982. Optimizing copper spheres for precision calibration of hydroacoustic equipment. J. Acoust. Soc. Am., 22(44): 151-156.

GANDINI FC \& MADUREIRA LSP. 2007. Prospecção acústica de Organismos Pelágicos e sua Integração com os Processos Físicos de Enriquecimento no Atlântico Sudoeste Brasileiro. In: BERNARDES RA, ROSSIWONGTSCHOWSKI CLDB \& MADUREIRA LSP. Prospecção pesqueira de espécies pelágicas de pequeno porte na Zona Econômica Exclusiva da Região Sudeste-Sul do Brasil. Série Documentos Técnicos do Programa REVIZEE - Score-Sul. São Paulo, Instituto Oceanográfico - USP. p. $9-25$.

KLEIN AHF, GRIEP GH, CALLIARI LJ \& VILLWOCK JA. 1992. Ocorrências de Concreç̃̃es Fosfáticas no Terraço do Rio Grande. In: Congr. Bras. Geol., 37., 1992, Camboriú, SC. Resumos Expandidos... Camboriú, SC: SBG, p. 202-203.
MacLENNAN DN \& SIMMONDS EJ. 1992. Fisheries Acoustic. Chapman \& Hall, Fish and Fisheries Series, 5: $325 \mathrm{pp}$.

MERO JL. 1965. The mineral resources of the sea. Elsevier, Oceanography Series, v. 1, $312 \mathrm{pp}$.

MÖLLER Jr 00, PIOLA AR, FREITAS AC \& CAMPOS EJD. 2008. The effects of river discharge and seasonal winds on the shelf off southeastern South America. Cont. Shelf Res., 28: 1607-1624.

PINET P. 1998. Invitation to oceanography. Jones \& Bartlett Pub. 508 pp.

PIOLA AR, MÖLLER Jr 00, GUERRERO RA \& CAMPOS EJD. 2008. Variability of the subtropical shelf front off eastern South America: Winter 2003 and Summer 2004. Cont. Shelf Res., 28: 1639-1648.

RIGGS SR \& BURNETT WC. 1990. Continental margin environments and mineral resources (COMEMIR). Plain of action. A research project of the Intergovernmental Oceanographic Commission - United Nations Ocean Affairs and Law of the Sea Branch. Ocean Science in Relation to NonLiving Resources (OSNLR), 8 pp.

RIGGS SR \& SHELDON RP. 1990. Paleoceanographic and paleoclimatic controls of the temporal and geographic distribution of upper $\mathrm{Ce}-$ nozoic continental margin phosphorites. In: BURNETT WC \& RIGGS SR. Phosphate deposits of the world. Cambridge University Press, v. 3, p. 207-222.

SANDWELL DT, SMITH WHF, GILLE S, JAYNE S, SOOFI K \& COAKLEY B. 2001. Bathymetry from Space: White paper in support of a highresolution, ocean altimeter mission. Disponível em

$<$ http://topex.ucsd.edu/marine_grav/white_paper.pdf > Acesso em: 1 abr. 2008.

SANDWELL DT, GILLE ST \& SMITH WHF. 2002. Bathymetry from Space: Oceanography, Geophysics, and Climate. Geosciences Professional Services, Bethesda, Workshop, Maryland, 24 pp. Disponível em: $<$ <ttp:www.igpp.ucsd.edu/bathymetry_workshop > . Acesso em: 1 abr. 2008.

SILVA CG \& MELLO SLM. 2005. Nossas riquezas no mar: Recursos não-vivos. In: Ministério da Educação, Secretaria da Educação Básica. 0 mar no espaço geográfico brasileiro. Coleção Explorando o Ensino, 8(5): 160-178.

SIMRAD. 1996. Simrad EK500: Fishery research echo sounder. Instruction Manual (Operator manual). $232 \mathrm{pp}$.

SMITH WHF \& SANDWELL DT. 1997. Global seafloor topography from satellite altimetry and ship depth soundings. Science, 277: 1956-1962.

SMITH WHF \& WESSEL P. 1990. Gridding with continuous curvature splines in tension. Geophysics, 55: 293-305.

WESSEL P \& SMITH WHF. 1998. New, improved version of Generic Mapping Tools released. EOS Transactions AGU, 79(47): 579. 


\section{NOTAS SOBRE OS AUTORES}

Marcelo Peres de Pinho. Graduado em Engenharia de Computação pela Universidade Federal do Rio Grande (2002) e Mestre em Oceanografia Física, Química e Geológica pelo PPGOFQ/FURG (2009). Atualmente trabalha junto ao Laboratório de Tecnologia Pesqueira e Hidroacústica do Instituto de Oceanografia da FURG. Tem experiência na área de Ciência da Computação, com ênfase em Metodologia e Técnicas da Computação e Geoprocessamento. Atua na área de Hidroacústica aplicada tanto na determinação da Geomorfologia Submarina, quanto no mapeamento, estimativa de abundância e manejo de recursos pesqueiros pelágicos. Participa de projetos de mapeamentos de fundos e pesquisas junto a empresas de petróleo com levantamento de dados e avaliações de impacto.

Lauro Saint Pastous Madureira. Graduado em Oceanologia pela FURG (1980) e Ph.D. pela University of Cambridge em 1992. Desde 1993 é Professor Associado III do Instituto de Oceanografia da Furg, onde atua na graduação em Oceanologia e na pós-graduação em Oceanografia Biológica. Coordenou e executou as atividades de Prospecção de Recursos Pelágicos do Programa REVIZEE nas costas sul, sudeste, leste e nordeste do Brasil, com metodologia hidroacústica. Atualmente tem projetos de pesquisa de prospecção e avaliações de biomassa de sardinha, anchoita e outros peixes pelágicos. Coordena e executa projetos de mapeamentos de fundos e pesquisas junto a empresas de petróleo com levantamento de dados e avaliações de impacto.

Lauro Júlio Calliari. Possui graduação em Oceanologia pela Universidade Federal do Rio Grande (1975), mestrado em Geociências pela Universidade Federal do Rio Grande do Sul (1980) e doutorado em Oceanografia Geológica - Virginia Institute of Marine Science (1990). Atualmente é Professor Titular da Universidade Federal do Rio Grande. Tem experiência na área de Oceanografia, com ênfase em Oceanografia Geológica, atuando principalmente nos seguintes temas: morfodinâmica costeira com enfoque em praias arenosas marinhas e estuarinas, sedimentologia e recursos minerais do mar associados à zona costeira. Tem atuação também em aspectos relacionados ao gerenciamento costeiro usando os princípios da morfodinâmica.

Gilberto Henrique Griep. Possui graduação em Oceanologia pela Universidade Federal do Rio Grande (1977). Atualmente é Professor Adjunto III da Universidade Federal do Rio Grande. Tem experiência na área de Geociências, com ênfase em Sensoriamento Remoto, atuando principalmente nos seguintes temas: batimetria, sedimentologia, sondagem, mapa de sensibilidade e petróleo.

Caroline Vieira Cooke. Possui graduação em Oceanologia pela Universidade Federal do Rio Grande - FURG (2005). Concluiu o mestrado em Oceanografia Biológica pelo Programa de Pós-graduação em Oceanografia Biológica - PPGOB/FURG em janeiro de 2009. Tem experiência na área de Oceanografia, com ênfase em Hidroacústica aplicada tanto na determinação da Geomorfologia Submarina, quanto no mapeamento, estimativa de abundância e manejo de recursos pesqueiros pelágicos. 